\title{
O PAPEL DAS ESQUERDAS NO MUNDO
}

\section{THE ROLE OF LEAVES IN THE WORLD}

\section{EL PAPEL DE LAS IZQUIERDAS EN EL MUNDO}

\section{Entrevista com}

Constanza Moreira, Consuelo Sánchez, Héctor Diaz Polanco, Juan Carlos Monedero, Michel Wieviorka

\section{Organizada por}

Rebecca Igreja, Camilo Negri e Jacques de Novion Universidade de Brasília Brasil

Vídeos disponíveis: https://www.youtube.com/channel/UCQz1zhkRhA9q24OncEbDkBQ

\section{Resumo:}

Entrevista realizada com Constanza Moreira, Consuelo Sánchez, Héctor Diaz Polanco, Juan Carlos Monedero e Michel Wieviorka, por Rebecca Igreja, Camilo Negri e Jacques de Novion, sobre o "Papel das esquerdas na atualidade".

Palavras-chave: esquerdas mundiais. disputas políticas. América Latina.

\section{Resumen:}

Entrevista realizada con Constanza Moreira, Consuelo Sánchez, Héctor Diaz Polanco, Juan Carlos Monedero y Michel Wieviorka, por Rebecca Igreja, Camilo Negri y Jacques de Novion, sobre el "Papel de las izquierdas en la actualidad".

Palabras clave: izquierdas mundiales. las disputas políticas. América Latina. 


\begin{abstract}
:
Interview with Constanza Moreira, Consuelo Sánchez, Héctor Diaz Polanco, Juan Carlos Monedero and Michel Wieviorka, performed by Rebecca Igreja, Camilo Negri and Jacques de Novion, about the "Role of leftists in the present".
\end{abstract}

Keywords: world lefts. political disputes. Latin America.

A

o final do século XX, mudanças significativas impulsaram uma nova ordem global neoliberal. $O$ avanço do capitalismo financeiro e de políticas de austeridade impõem reacomodações do sistema e dos interesses capitalistas, desestruturação dos direitos sociais e dos trabalhadores, o fortalecimento dos setores de ultradireita, o abismo da desigualdade que empurra a maioria da população global para condições desumanas de vida. Nesse cenário conflitivo e assustador, qual seria, para você, o papel das esquerdas nesse contexto?

A fines del siglo XX cambios significativos impulsaron un nuevo orden global neoliberal. El avance del capitalismo financiero y de políticas de austeridad imponen reacomodos del Sistema $e$ intereses capitalistas, desestructuración de los derechos sociales y de los trabajadores, el fortalecimiento de los sectores de ultraderecha, el abismo de la desigualdad que empuja la mayoría de la población global a condiciones deshumanas de vida. ¿En ese escenario conflictivo y abrumador, cual sería para usted el papel de las izquierdas en este contexto?
Juan Carlos Monedero: Prácticamente en todo el mundo la derecha, o la extrema derecha, está gobernando nunca con más del 30\% de los votos. Ni Emmanuel Macron (Francia, 2017-actual), ni Donald Trump (Estados Unidos de las Américas, 2017actual), ni Mariano Rajoy (España, 20112018), ni Michel Temer (Brasil, 20162018), ni Mauricio Macri (Argentina, 2015actual) o en ningún otro lugar. La pregunta es: qué está haciendo el otro $70 \%$ ?

Seguramente, mientras que la derecha y la extrema derecha está siendo capaz de reunir a ese $30 \%$, que lo construye, como una minoría consistente para gobernar, el otro $70 \%$ está fragmentado $\mathrm{y}$, por tanto, la pregunta es: cómo sumar ese $70 \%$ ?

Es bastante probable que en el siglo XXI sea muy complicado que la izquierda - que es mucho más exigente en cuanto a ideas, en cuanto análisis y a diagnósticos que la derecha -, pueda asomar ni siquiera $30 \%$ en un partido político unificado, con un único ideario y, por tanto, creo que es bastante más probable que la unificación de las fuerzas de la emancipación, que frene a la derecha y de la extrema derecha y que proponga alternativas, tenga más que ver con frentes amplios. Es decir, donde hay una fuerza que actúa como la nave nodriza, capaz de reunir en torno a ese $30 \%$, pero que luego el resto de agregados hasta sumar 50 o $60 \%$ de los votos - sean pequeños partidos 
que pueden tener ideologías más excluyentes, pero que tengan un mínimo denominador común compartido con esta nave nodriza y con los demás, y que están dispuestos a unirse a esa pelea para intentar abrir el camino en el siglo XXI.

Eso nos obliga a hacer más laicos a los partidos, a entender que las ideologías fuertes, como ha tenido la izquierda durante el siglo $\mathrm{XX}$, que han llevado a que, si tú tenías diferencias, montabas una internacional diferente, como La Segunda Internacional, La Tercera, La Cuarta... Es decir que, en virtud del diagnóstico, la izquierda ha sido muy amiga de separarse. Yo creo que hay que hacer más laicos a los partidos e incorporar de las tres almas de la izquierda - el alma reformista, el alma revolucionaria y el alma rebelde -, e incorporar la que hemos hecho menos caso, que esté el alma rebelde. Es Bakunin frente a Marx, es Trotsky frente a Stalin, es Rosa Luxemburgo frente a Lenin. Creo que ese socialismo más libertario es el que va a tener que entender de alguna manera que esa unidad va a tener que ser mucho más flexible qui como ha sido la izquierda durante siglo $\mathrm{XX}$ y en nombre de esa flexibilidad vamos a tener que tener oídos para esa expresión, un mundo en el que quepan muchos mundos, y esa lógica de romper con la exclusión, de terminar con la idea de «quítate tú que me pongo yo », y sustituirlo por « vamos a poner más sillas en la mesa ».

Constanza Moreira: Primeiro eu acho que aqui na América Latina os direitos nunca estiveram assegurados. Não é que com o neoliberalismo nós estamos recuando de Estados de Bem-Estar que estavam superbem instalados. Não estavam instalados nada, menos aqui no Brasil.
Penso até no Uruguai, que é um país bastante avançado, nós tivemos a lei prevendo oito horas aos trabalhadores rurais só agora no século XXI. Então, a gente não pode pensar que o neoliberalismo veio destruir um Estado de Bem-Estar anterior ou direitos largamente assumidos. Coisa que sim está acontecendo na Europa, mas nós apenas estávamos criando um Estado quando veio isso que a gente chama de neoliberalismo, mas que é uma face a mais do Capitalismo. Também não temos que exagerar tanto colocando a questão no neoliberalismo. É o capitalismo, mas são capitalismos diferentes: um capitalismo muito globalizado, com uma grande uniformização de normas de comércio, de regulações financeiras, que vão limitando a margem, já pequena, política que nossos países têm de projetar políticas soberanas. Esse é o momento mais complicado para nós, essa grande globalização, com o predomínio do capital financeiro sobre o produtivo. E qual é o papel das esquerdas? Bom, essas esquerdas que estão ganhando ou perdendo a luta democrática, o estão fazendo dentro da democracia capitalista. Então como nós vamos construir, a longo prazo, uma perspectiva diferente do capitalismo e, ao mesmo tempo, construímos democracia no marco da democracia representativa liberal, que nós herdamos do passado. A luta das esquerdas tem que ser concentrada sempre em: as demanda por soberania nacional frente a globalização; a demanda por direitos, direitos econômicos, direito ao salário mínimo, direito às leis sociais, direitos laborais - nós estamos nesta luta -, direitos civis - não podemos ser assassinados pela rua por sermos pretos, homossexual -, direitos da mulher - a mulher está sofrendo uma violência selvagem -, etc. Então estamos trabalhando pela expansão dos 
direitos, pela justiça social, pela regulação do capitalismo - nós estamos enfrentando a pior face da desregulamentação do capitalismo -. E a mais importante tarefa cultural que a esquerda tem, é a velha e antiga tarefa da esquerda que é «outro mundo ser possível ». As coisas não têm porquê ser como são. Não há uma realidade dada, a desigualdade não é natural, é construída politicamente. E, ao mesmo tempo, o que a esquerda tem que fazer é lutar contra a solidão política, lutar para que a gente possa confiar uns nos outros e nos associemos para lutar por condições de vida. Acho que essa é grande tarefa da esquerda desde o princípio dos tempos até agora.

Michel Wieviorka: Eu venho de um país, a França, onde a esquerda está completamente decomposta. O Partido Comunista não representa mais grande coisa, o Partido Socialista se desmoronou durante as últimas eleições, após 5 anos catastróficos de uma presidência de um chefe de Estado socialista e a esquerda da esquerda está sem perspectiva eleitoral. Assim, a esquerda grita, mas não pode nada realmente mudar. Portanto, há países em que a esquerda deve se reconstruir completamente e eu creio que ela se reconstruirá completamente somente quando for capaz de se apoiar sobre novos movimentos sociais, sobre novas contestações culturais, de escutá-los, de compreendê-los e de motivá-los vez ou outra. Mas há outros países onde a esquerda existe e que se constrói ou se reconstrói. Nós somos aqui, hoje, nesse momento que eu lhe falo, em Brasília, em um contexto em que discutimos sobre a experiência mexicana, MORENA, da experiência espanhola, do Podemos, países que nos mostram que a esquerda pode se construir ou pode se reconstruir. Portanto, devemos ser prudentes em um julgamento muito negativo, muito preocupante. Sim, a social democracia vai mal, o comunismo é desacreditado, mas existe em alguns países pessoas que começam a inventar a nova esquerda.

Héctor Diaz Polanco: Primero de todo, estamos absolutamente obligados a tratar de comprender a fondo el nuevo giro que tuvo la sociedad humana global, a raíz de estos de eses dos fenómenos interrelacionados. Es decir, la etapa del capitalismo neoliberal, por un lado, y articulado con él, el llamado proceso de globalización. Tengo la idea de que en parte la imposibilidad de construir propuestas alternativas está íntimamente vinculado con el hecho de que no ha habido una comprensión suficiente todavía de todas las implicaciones de la globalización, de sus resortes secretos - y algunos no tan secreto - y muy evidentes. Usted mencionó en su pregunta algunos de ellos: la precarización del trabajo, el control y/o destrucción de los sindicatos, en los procesos de acumulación por desposesión como la llama Harvey -, el proceso de acumulación ahora basada en la privatización - incluso de los acumulados sociales en manos del estado - y el proceso sociocultural más importante del neoliberalismo globalizador que es el proceso de profundización cada vez mayor de la individualización de la sociedad. De tal manera que el proceso de globalización implica por tanto una sistemática destruición de comunidades. Comunidades en sentido amplio $\mathrm{y}$ en sus diversas vertientes, no solo refiriéndonos a las comunidades tradicionales que conocemos 
- como las comunidades indígenas, como las comunidades campesinas, sino también las comunidades urbanas, comunidades de ciertos tipos religiosos, sociales, culturales-de tal manera que si nosotros queremos recuperar la senda de la transformación, tenemos, primero, que entender esta complejidad del proceso de globalización y segundo definir a partir de esta con mejor comprensión los hilos básicos por los cuales podemos jalar las propuestas que sean eficaces frente al proceso de globalización del capital globalizado. Esto tiene un aspecto importante de carácter político e ideológico, algo que ya han señalado varios de los pensadores contemporáneos, el hecho de que el neoliberalismo también es un proyecto cultural y que tiene vertientes políticas culturales como esta de que la señalada por varios autores, pensadores contemporáneos, de que ha llegado un momento en que es más fácil para los miembros de la sociedad concebir la destrucción del mundo que de concebir la destrucción del capitalismo. Es decir, se ha ido naturalizando la idea de que el capitalismo es una especie no del sistema social e histórico que nace crece se desarrolla y muere, sino que es una forma natural de vivir en sociedad, y que la única forma de concebir el proceso productivo, $\mathrm{y}$ que es la única forma de organizar el consumo, y que es la única forma de vivir en cultura. Si se ha creado un sentido común naturalizador de los procesos históricas. Tenemos, entonces, que remontar esto y vencer esta esta tendencia que se ha impuesto.

Consuelo Sánchez: El papel de la izquierda precisamente es luchar pesadamente contra el neoliberalismo, que es la fase actual del capitalismo y hacer un cambio, una transformación profunda, resolver las desigualdades, construir sociedades justas e igualitarias. Tenemos muchos tipos de desigualdad: tenemos desigualdades socioeconómicas, tenemos desigualdades socioculturales y políticas. La inmensa mayoría de la población está excluida de la toma de decisiones políticas en nuestros países, es una minoría y, generalmente, una minoría política aliada a la oligarquía - si no es que esta és la élite política ella misma. Un estado dedicado a hacer, crear las condiciones para los negocios del capital y no para cumplir las funciones en relación con la sociedad, con el pueblo, etcétera, y como ya decíamos que se ha dedicado a cancelar derechos, pues desde la izquierda la gran preocupación, el gran interés, es recuperar el control del estado, crear otra forma de estado, porque eso se ha venido planteando en américa latina: la refundación de ese estado. Un estado comprometido con la sociedad, de crear, incluso organizar a la sociedad y al estado en función de las necesidades de esa sociedad y de ese pueblo, lo que implica una economía diferente, pensada de manera diferente, en función de las necesidades de la gente, del bienestar de la gente y no la economía como hasta ahora, con el neoliberalismo, una economía pensada en función del beneficio y de la ganancia para unos cuantos sino crear otra economía en función del beneficio de todos, para satisfacer las necesidades de todos, de todos los forman parte de ese país. Pero también necesitamos resolver otro tipo de desigualdades de orden sociocultural que ahora se hacen más evidentes que estuvieron en otras épocas pero ahora sobre todo los años 1970 y 1960 - se hacen presentes, se han visibilizado, han tratado 
de visibilizar sus luchas, políticamente, como las mujeres, con los movimientos feministas, con reclamos muy particulares que también implica transformaciones de la sociedad, de cómo se conciben las relaciones de género, como transformar las relaciones del poder y crear y construir sociedades donde se respete a la mujer y los derechos que vienen reclamando las mujeres. Y la otra es la de los pueblos indígenas, que en nuestros países la presencia de los pueblos indígenas es importantísima. Y no importa el número, el porcentaje de la población siendo minoría o mayoría: no importa. Esta es una población que hay que atender porque ha vivido en condiciones de desigualdad y de exclusión total, entonces lo que se trata es de reconocer que es parte de nuestra sociedad, es parte de nuestra diversidad, de nuestra riqueza cultural, y que hay que incorporarle, reconocerle los derechos y qué justicia le corresponde. Y esto implica cambios importantes en la concepción de la propia nación y del estado porque implica reconocer, en términos de políticas públicas, en términos de gobierno, de autogobierno, implica cambios importantes como estamos viendo en el caso de Bolivia con la conformación del Estado Plurinacional. Y también la cuestión política. El régimen que ha existido desde la conformación de nuestros estados naciones de América Latina y en general en todos los países capitalistas, pues ha implicado una exclusión de las mayorías en la toma de decisiones. Entonces vamos a crear una sociedad donde todos podamos decidir y crear las instituciones que se requieren para que todos podremos decidir sobre el lugar nuestro país y sobre las cuestiones importantes, tanto en lo económico, en lo político, en lo social y en lo cultural.
$\mathrm{N}$ o campo das Ciências, historicamente, encontramos formas distintas de pensar o papel do conhecimento, da intelectualidade e da política. Como você analisa a relação entre ciência e sociedade, e como pensa a relação entre intelectualidade e militância política, ativismo social e comprometimento acadêmico?

¿En el campo de la Ciencia, históricamente se encuentran formas distintas de pensar el papel del conocimiento, de la intelectualidad y de la política? ¿Como usted analiza la relación entre Ciencia y sociedad, y como piensa la relación entre la intelectualidad y la militancia política, activismo social y comprometimiento

(engajamento) académico?

Juan Carlos Monedero: Las ciencias sociales no son igual que las ciencias naturales. Porque un saltamontes no cambia su comportamiento cuando se lo observas, pero el ser humano sí. Tenemos la obligación de ser objetivos, pero no somos neutrales y creo que eso debe ser como un axioma de la ciencia social: saber que cuando miramos a un sitio y nos miramos a otro, estamos perdiendo nuestra neutralidad. Pero esa pérdida de neutralidad no tiene en ningún momento que dejarnos caer en el error de no ser objetivos. Yo creo que para eso el intelectual tiene que tener herramientas incluso el intelectual orgánico, el intelectual activo en las transformaciones - no puede errar su lectura de la realidad haciendo wishfull thinking, es decir, pensando o deseando los cambios porque entonces no ayuda, no te ayuda a entender 
lo que pasa y por lo tanto no es útil. Es verdad que en las ciencias sociales tenemos que hacer una tarea de extrañamiento. Tú miras por la ventana y ves que el sol da vueltas alrededor de la tierra y es al revés, es la tierra la que da vueltas alrededor del sol. Igual ocurre en nuestra vida diaria: no necesitamos salirnos como "Neo", al final de "Matrix", $\mathrm{y}$ vernos desde fuera para poder entender lo que ocurre porque si no seguiremos siendo rehenes de no saber lo que nos pasa. Esa es la función de los intelectuales. Todos somos intelectuales como planteó Gramsci, todos pensamos, todos tenemos lenguaje, ideas, reflexiones, por es verdad que no todos tenemos la función del intelectual y la función del intelectual es quitar los velos, la función del intelectual es clarificar los procesos, la función del intelectual es establecer las causalidades y decir ' $S i ́$ ' A', entonces es bastante probable que ocurra B',, y esa tarea del intelectual solamente la puede desarrollar en la medida en que está dispuesto a molestar a cualquier tipo de poder, incluso el de tu propio partido o el del ámbito orgánico en el cual tú trabajas. Es verdad que cuando tú dices las verdades, eres incómodo. Y por eso yo creo que la diosa de las ciencias sociales es Casandra. Casandra le pidió Apolo el don de la adivinación se lo concedió, a cambio, de acostarse con ella. Cuando se lo concedió y Apolo quiso cobrarle la parte que le correspondía, ella se negó y entonces Apolo le escupió en la boca, condenándola que todo lo que salía de ella fuera escuchado como una mentira y la maldición de Casandra - que es la maldición del pensamiento crítico - es que entiendes que va a ocurrir, pero nadie te hace caso. No te hace caso el poder social porque le perjudica, pero a veces tampoco te hace caso tu universidad crítica, o tu movimiento social crítico, o tu partido político crítico, porque casi siempre los dirigentes críticos intentan encontrar un espacio de ubicación en lo existente y por tanto ese análisis diferente suele situarse como fuera de la posibilidad de continuar la misma lógica de las cosas. Yo creo que en ese sentido tenemos que hacer, como vengo contando siempre, una suerte de equilibrio dialéctico entre lo que hay y lo que puede haber. Tenemos que entender que en el siglo XXI es un siglo lleno de confusiones, $\mathrm{y}$ vamos a tener que primero hacer buenos diagnósticos y después de entender que parte del cambio es posible y qué parte no es posible y estar constantemente moviéndonos en la frontera. Yo creo que el pensamiento crítico es un pensamiento de frontera, no es un pensamiento de vanguardia, tampoco es un pensamiento de retaguardia, sino que es un pensamiento que, de alguna manera, va acompañando los más avanzados, pero va también acompañado de los más retrasados y de alguna manera están constantemente moviéndose la frontera y el problema es que se te mueves en la frontera la frontera es pocas leyes y tu piel tiene un precio, y por tanto los intelectuales de frontera que son los que necesitamos no van a ser los más numerosos.

Constanza Moreira: Vou começar com uma anedota. Eu estava discutindo com um professor da universidade que me dizia "Porque que a gente não pode olhar a sociedade com a distância com a qual a gente olha as estrelas, as árvores, mas a gente pode construir uma distância, como objeto de estudo?". E eu falei que o interessante é que a gente pode 
compreender os seres humanos e não pode compreender as estrelas, as plantas ou os bichos do mar. A gente tem uma compreensão disso, do que falava Webber, de empatia com os seres humanos, e nosso conhecimento sobre a sociedade é muito mais rico do que o conhecimento que temos das coisas que não podemos compreender pela diferença objetiva. Então, a ciência social sempre foi uma ciência prática. Essa é a ideia dos velhos gregos, a ideia de Aristóteles. O que quer dizer que a ciência social está a serviço do melhoramento do mundo. Não é uma ciência teórica na qual você está completamente abstraído de seu objeto. Esta característica da ciência social como ciência prática foi traída, digamos, convertida, na época de Hobbes, em que a ciência social, a ciência política, foi convertida em ciência teórica. Eu acho que essa é uma primeira reflexão, recuperar a raiz da práxis na ciência social. Senão ciência social faz práxis de qualquer maneira. Economistas estão sempre fazendo prática, informando os governos. Então, se você vai fazer práxis, que você vai fazer de qualquer forma, faça uma práxis lúcida, com lucidez. Em segundo lugar, eu acho que o conhecimento é uma coisa muito transformadora, tem um potencial muito revolucionário, então, houve também a construção da "academia" como separada do mundo real. Muito platônica isso, não é? Muito platônica essa ideia de que você vive no mundo das ideias. Vou dizer uma coisa muito simples: quem está pagando a todos os acadêmicos para ganharem o seu salário é o estado, é a população toda, então você tem que devolver - e esse é o sentido de construção cidadão - você tem que devolver à sociedade o que a sociedade te deu. Porque educação está sendo paga pela sociedade toda, a pesquisa científica está sendo paga pela sociedade toda. Então você não pode gastar milhões, milhões e milhões de dólares para descobrir o "Viagra". Não: você tem que gastar milhões de dólares na luta contra o câncer. Este é o processo do capitalismo dentro da ciência: o objetivo da tua pesquisa científica está determinado pelo mercado, pelos interesses do capitalismo, pelos interesses da pequena população que vive muito bem no mundo. Não, você tem o compromisso, sempre tem o compromisso com a população toda.

Michel Wieviorka: Quando falamos de ciências, nós pensamos, geralmente, na verdadeira ciência, na ciência dura, na ciência não humanas, em comparação às ciências humanas. Pensamos também ao que está em relação a medicina, a saúde. Nós pensamos em tudo que permite evitar a morte, ou seja, nós pensamos a astrofísica, no conhecimento do ser vivo, pensamos em muitas coisas, e eu penso que nesse ponto de vista, progressos gigantes foram logrados e são, talvez, queridos em nossas sociedades. Onde a questão se torna diferente é quando falamos da questão dos intelectuais. Eu penso que nós vivemos até os anos 50, 60, quando falamos da França, talvez mais tarde em outros países, nós vivemos o final de uma época na qual o intelectual era uma grande figura, um intelectual público; o modelo era Jean Paul Sartre. Isso acabou por agora. E em seguida, nós vimos o início de grandes intelectuais que representavam de uma maneira ou de outra o mundo das grandes ciências humanas sociais. Grandes historiadores, grandes filósofos, grandes sociólogos, 
cientistas políticos, e essas pessoas tiveram uma importância considerável nos anos 70, até que o modo de pensar dominante que era o deles, o estruturalismo, fosse por sua vez desconsiderado ou enfraquecido. Nós entramos em um novo período onde os intelectuais públicos clássicos, eu acho, pesam menos do que no passado e quando milhares de pesquisadores em ciências humanas e sociais constituem um tipo de intelectual coletivo que contribui muito para a vida coletiva, porque esses pesquisadores têm competência, conhecimento. Eles falam, a princípio, daquilo que conhecem, que estudam. O problema é saber como eles podem articular a produção de conhecimento, a difusão desse conhecimento, com a ação política e com a ação pública. Eu penso que no futuro nós teremos cada vez mais ocasiões de encontro entre o mundo da pesquisa em ciências humanas e sociais e o mundo da ação pública, da contestação, da ação política e que esse encontro se fará com atores que não se confundirão um com os outros, mas que se falarão.

Héctor Diaz Polanco: Eso depende de la perspectiva y la visión que uno adopte respecto al intelectual. Si uno reduce el papel, el perfil del intelectual al que se dedica a actividades científicas o de creación en el campo de la literatura, en las artes plásticas, etcétera, el erudito, al filósofo al que se dedica a construir pensamientos e ideas, entonces la relación es una relación con la sociedad poco definida para los fines de definir, a su vez, el vínculo con el proceso político. Pero si uno adopta una visión de intelectual que implica necesariamente la articulación del trabajo en esos campos con las contradicciones de la sociedad - que es lo que hace, por ejemplo, Sartre, en su trabajo sobre este tema - entonces entenderá que el carácter del intelectual hace una figura de hombre público que no necesariamente se separa de su tarea como investigador, como analista, como historiador, como creador en el arte, sino que a partir de ese trabajo descubrir las contradicciones de la sociedad, y en consecuencia se convierte en una persona comprometida con la resolución de esas contradicciones. Y entonces tiene usted a alguien que hace estas actividades habitualmente asociadas con lo intelectual, pero eso puede ser simplemente un académico, por ejemplo. Lo que hace a un intelectual es que haga ese trabajo y además asuma un compromiso de carácter público que lo hace participar en los procesos de su sociedad, justamente porque al entender esas contradicciones, por ejemplo, el hecho de que la sociedad esté organizada supuestamente para resolver los problemas de sus miembros y en lugar de eso produce una sociedad cada vez más desigual, una sociedad donde prima la explotación, la subordinación, la exclusión etcétera, al comprender por ejemplo, sólo como ilustración, este tipo de contradicciones dedica esfuerzo público, no sólo en el ámbito privado, o en el cubículo del científico, y en consecuencia hace de ese compromiso una especie de lucha pública social por abordar esa contradicción que descubrió su propia actividad como científico pensador o artista.

Consuelo Sánchez: Yo soy profesora investigadora de la Escuela Nacional Antropología Historia, y yo siempre en mi 
trabajo, mis investigaciones, mis inquietudes, siempre está asociada a conocer y tratar de encontrar soluciones a los problemas que se presentan para distintos sectores de la población en nuestro país y en otras partes. Yo me dedico a la cuestión indígena y a la autonomía de los pueblos, de modo que, pues mis investigaciones tienen que ver con eso, con el tema de la autonomía, en términos teóricos, y también en la práctica, trabajando con las poblaciones indígenas, discutiendo, debatiendo con ellos los proyectos de construcción y además de investigaciones de otro tipo, etnográficas, etcétera. Y además he participado tanto con el ese tema, como asesora en el diálogo de San Andrés, de donde salieron los acuerdos de San Andrés, y después en México, en la Ciudad de México, hemos trabajado también con los pueblos y barrios originarios y he participado en Morena porque quiero que en mi país cambien las cosas. La situación en México, ustedes saben, todo lo que se enteran por los medios de comunicación, ahí tenemos se aplica el neoliberalismo de la manera más terrible. Se ha ido vendiendo todo toda nuestra riqueza, se ha privatizado todo, mercantilizado todo, y ha aumentado la pobreza, la desigualdad, la injusticia, la militarización del país, el narcotráfico, la corrupción etcétera. Y, pues, uno no puede estar al margen de lo que sucede en el país y no involucrarse. Entonces es un deber y un compromiso involucrarse con el país para buscar el camino de la transformación y hacerlo políticamente. No hay otra: hay que hacerlo políticamente. Además somos también entes políticos y tenemos el derecho a hacerlo y que nuestras investigaciones también pueden servir a ese proceso de cambio, de transformación, y de hecho creo que como investigadores podemos aportar muchísimo en ese cambio yo me invitaron a hacer y fui constituyente, diputada constituyente, en la Asamblea Constituyente de la Ciudad México, que elaboró su primera Constitución, y la verdad es que creo que la presencia de los que tenemos una formación porque participamos por parte de Morena pues varios que tenemos una formación filósofos, politólogos, juristas, etcétera que participamos ahí y cada uno, pues es una aportación importantísima. Importantísima para que finalmente logramos una muy buena Constitución porque además somos de izquierda, queremos cambio y transformación creemos que en la ciudad se podrían hacer muchos cambios, que podrían impactar al conjunto del país y ahí trabajamos, y toda nuestra experiencia, todos nuestros conocimientos, ayudaron muchísimo para que salieran una muy buena constitución, que ha sido la verdad felicitada por quienes la conocen porque sí se lograran cosas muy importantes y ahí, la verdad, nos dimos cuenta, y quién se ha enterado sobre todo investigadores que no quieren saber nada de la participación política donde se enteran de todo lo que uno puede lograr, porque tiene argumentos, porque conoce, etcétera, y que se pueden lograr muchas cosas, se entusiasma. Y además que es nuestro deber, los científicos sociales, muchos de nosotros, trabajamos en instituciones públicas y nuestro salario, pues, viene de recursos públicos entonces nuestro deber es vincularnos a los temas, a las problemáticas sociales, y buscar soluciones a esos problemas es uno de nuestro deber y nuestro compromiso como investigadores y profesores. 
$\mathbf{N}$

a América Latina e no

Caribe, o avanço das demandas neoliberais

impulsaram, no início do século XXI, um conjunto de mudanças políticas nos países da região. Denominados de governos populistas, pós-neoliberais, progressistas de esquerda, híbridos, entre outros. Como você avalia essas experiências recentes e como interpreta essa diversidade de projetos e alternativas? Em resumo, como observa o papel das esquerdas no continente?

En América Latina y el Caribe el avance de las demandas neoliberales impulsaron, en principios del siglo XXI, un conjunto de cambios políticos en países de la región. Denominados de gobiernos populistas, posneoliberales, progresistas de izquierda, híbridos, entre otros, ¿cómo usted evalúa esta experiencia reciente y cómo interpreta esa diversidad de proyectos y alternativas? ¿En síntesis, como observa el papel de las izquierdas en el continente?

Juan Carlos Monedero: Creo que los gobiernos de cambio desde la victoria de Hugo Chávez, en diciembre del 1998, marcó un punto de inflexión. Estados unidos estaba muy enredado en la guerra en Irak creo que eso permitió que América Latina, que fue el primer continente en sufrir el modelo neoliberal, fuera también el primero en plantear alguna forma de superación. Hoy sabemos que ha habido problemas. Yo creo que la agenda post neoliberal nunca fue una agenda post capitalista, y de alguna manera se establecieron redistribución es de la renta, pero no ese cambio en modo alguno de la estructura. Se construyeron clientes con mayor capacidad de consumo, pero nos hicieron ciudadanas y ciudadanos. Creo que no estuvo a la misma altura la construcción de un cambio en la capacidad de consumo con el incremento de cultura que hubiera significado que esa gente, esos 70 millones de latinoamericanos que han salido de la pobreza desde eso desde el año 2000, después estuvieran siendo fuerzas activas de la defensa de esos gobiernos, y no ha sido el caso. Creo que el ejemplo más emblemático es Brasil, donde esos 32 millones de personas que salieron de la pobreza no encontraron razones para manifestarse en la calle contra el falso impeachment contra Dilma Rousseff. En ese sentido, yo creo que hay que celebrar que hubiera un incremento del consumo, que gente salía de la pobreza, que llegase por vez primera sanidad educación a sitios donde antes no llegaban, tuvieran una dignificación urbanística en las zonas tradicionales de favelas, de villas miseria, de ranchos en América Latina, pero parece evidente que faltó como trasladar eso a un incremento de la conciencia y ahí también es muy relevante algo que apuntó John Holloway cuando él decía aquello de cambiar el mundo sin tomar el poder. Yo creo que fue un análisis equivocado porque es imposible que tú reviertas la lógica neoliberal si no tienes el aparato del estado. Pero sí que la amenaza del estado, sobre la cual advertía Holloway - de que había que tener cuidado porque el estado de termina devorando-, era una advertencia legítima. Y yo creo que los casos de corrupción que hemos visto en todos estos países de cambio y que han reforzado el ataque por parte de la derecha, son parte de un error que no tenía por qué haber tenido lugar. No está escrito en ningún sitio que estos gobiernos de Brasil, de Argentina, de Ecuador, de Venezuela, tuvieran que tener casos de 
corrupción tan sonados. No era necesario, no está escrito en ningún sitio. Yo creo que fue esa parte de descuido, de no ser conscientes de que cuando tú ocupas un aparato del estado - que se ha construido durante 200 años por las élites -, es bastante probable que la propia lógica de ese estado que termine devorando. Y, por tanto, de cara al futuro, yo creo que las izquierdas tienen que entender que hace falta un pensamiento diferente y estructuras diferentes. Va a tener que ser el cambio con partidos políticos diferentes, con una manera diferente de estar en el aparato del estado y, la más evidente, que las formaciones políticas de cambios, para tener que diferenciar entre su presencia a los gobiernos y su presencia como partido es movimiento. $\mathrm{Y}$ hay algo que tenemos que desterrar que es que toda la gente que dirige el partido movimiento coincida con gente que está en las instituciones, porque entonces no hay ningún sitio donde poder construir algo diferente.

Constanza Moreira: O García Linera, o Vice Presidente da Bolívia - e, aliás, um grande intelectual -, ele fala da "Década de Ouro" dos progressismos latinoamericanos, que começa mais ou menos nos anos 2000 e vai até 2015, eu acho que o Golpe de Estado contra a Dilma é uma boa data para marcar o impasse que esta "Década de Ouro", esta década virtuosa da política está experimentando agora. Tem uma enorme diversidade de ideias e projetos chamados de esquerda e progressistas. Todos muito diferentes: em alguns casos tem um Presidente de esquerda, mas que governa com coalisões de direita; em outros casos tem partidos de esquerdas; em outros são partidos, mas surgidos de movimentos sociais; tem de tudo. O que une esses projetos? Bom, primeiro, que eles se uniram, todos juntos: criaram o Banco do Sul, criaram a CELAC, criaram a Unasur, apesar da diversidade das esquerdas, eu acho que o Chávez, o Kischner, Lula, Tabaré Vázquez, nunca tiveram problema em encontrar suas coincidências. A diferença é uma diferença teórica, mas a prática os juntou. Lutando contra quem? Lutando contra os Estados Unidos, para sair de sua área de influência; lutando por um projeto regional, para compartilharmos nossos recursos estratégicos - o petróleo, os minerais, enfim -; eu acho que houve uma coincidência na práxis de todos esses projetos, apesar das diferenças que eu acho mais resgatável da "Década de Ouro" como chama Garcia Linera, e que consistiu no empoderamento das mulheres, dos indígenas, dos pretos, dos trabalhadores e dos pobres. Todos eles mais ou menos fizeram isso, de forma diferente. A luta para que a subalternidade política fosse se transformando em sujeito da política. Isso é uma coisa importante em todos esses projetos. A segunda coisa é que todos eles lutaram, de uma forma ou de outra, contra os grandes poderes mundiais - Estados Unidos, União Europeia -, eles foram se alinhando com o Sul da África, com a Índia, com a China, todos eles no mapa global lutaram contra o capitalismo, contra os donos do capitalismo central. Em terceiro lugar, todos eles lutaram para recuperar a capacidade do Estado de ter recursos estratégicos próprios - as empresas públicas, o petróleo, no caso da Bolívia a luta pelos hidrocarbonetos, no caso do Uruguai a luta pela água -, então, todos eles lutaram para que os recursos estratégicos permanecessem nas mãos da nação, através do estado. $\mathrm{E}$ todos eles enfrentaram a direita, por isso que são de esquerda: a direita é Macri na Argentina, é - não só - o 
PFL no Brasil, o partido do Fernando Henrique Cardoso, que realmente tomou partido pelo golpismo. Então eu acho que este empasse que nós estamos sofrendo dá para que a agente tire a venda dos olhos e enxergue onde está à direita e onde está à esquerda, apesar de todas as distinções teóricas e intelectuais que existem. Você tem esquerda onde está a luta dos trabalhadores, das mulheres, dos pretos e da parte mais pobre da sociedade, e você está com a direita quando está com o status quo. E pronto. Também as coisas têm que ser um pouquinho mais simplificadas, politicamente, para termos um mapa global. Depois você, dentro, faz todas as distinções que quiser.

Michel Wieviorka: Se consideramos a América Latina, nós somos confrontados com uma grande diferença de experiências. No México, para partir do mais ao norte, reconstrói-se a esquerda ao redor do MORENA. Se consideramos a Venezuela, no entanto, a experiência do Chaves, que já foi muitas vezes criticada, que se transformou em um regime muito preocupante. Eu acho que entre aqueles que continuam a querer continuar a falar de maneira positiva da Venezuela e que tem essa ideia que nós não podemos abandonar a Venezuela completamente e que nós devemos ter uma certa dignidade, mas pessoa não duvida hoje em dia da natureza desse regime. Em Bolívia, Evo Morales conseguiu tirar o país, de alguma forma, desse monopólio dos brancos, dos dominantes, que faziam que todo o mundo indígena estivessem excluídos e que ele fez entrar na sociedade; No Brasil, nós tivemos, apesar de tudo, essa, experiência construtiva, LULA, Dilma e depois em seguida, a grande catástrofe ligada à corrupção, o que é terrível, e podíamos continuar assim, no Chile teve a esquerda com Bachelet, no Equador, Correia e portanto, o que me parece é que a mundialização da economia, a globalização neoliberal não significa necessariamente, portanto, a direitizaçao do sistema político, o desmoronamento da esquerda, não necessariamente. Há outras respostas que são possíveis nesse universo que é efetivamente dominado pelo mercado, dinheiro e pelas grandes empresas.

Héctor Diaz Polanco: Yo creo que precisamente a fin del siglo pasado e inicio de este se inicia un ciclo de transformaciones en América Latina. No tiene un patrón común que determine los procesos absolutamente similares, pero si hay grandes tendencias que lo caracterizan. El hecho de que para empezar implicó un renacimiento de los movimientos sociales. Movimientos sociales que ya dieron origen a la construcción de organizaciones políticas, no necesariamente en forma de partido, pero también en forma de partido, que permitió por la vía electoral - que es otra novedad, que rompió, digamos, con la tradición de que izquierda era sinónimo de vía armada -, y que permitía entonces conquistar los aparatos de gobierno, llamar a una constituyente, y hacer transformaciones a partir de la modificación del entramado jurídico político basado, justamente, en la fuerza de estos movimientos. Esto es lo que ha permitido que, en países como Ecuador, Bolivia, el propio Brasil en su momento, el Uruguay, etcétera, se hayan realizado estos cambios que han sido fundamentales. Es un cambio importantísimo. En primer lugar, porque la izquierda hasta ese momento, en la mayoría de los países latinoamericanos, con las 
salvedades que conocemos - el caso de Cuba, por ejemplo, posteriormente en el caso de Nicaragua -, pero dejando esos casos del lado, en general la izquierda había sido una fuerza relativamente marginal en América Latina. Y en esta fase se convirtió en una fuerza fundamental en el continente y llegando a dominar en algunos lugares ya más de 10 años en el escenario político, incluso el proceso de transformaciones que era inconcebible apenas hace unos cuantos lustros, entonces que era una fase muy importante. Ahora la discusión que tenemos pendientes, ese es llamado "Ciclo de Transformación”, ese es un debate que está muy vivo, ha llegado a su fin. Es decir, lo que se ha llamado el fin del ciclo de transformaciones que supuestamente daría lugar, en de una manera pendular, a un ciclo digamos reaccionario, conservador, que haría retroceder estos cambios y que haría retroceder de nuevo a la izquierda, es un debate en marcha. A mi juicio hay que esperarse un poco, dar lugar a ciertos procesos que se están dando en América Latina, incluyendo México que están avanzando en la dirección transformadora, a ver si estos estos procesos cuajan para poder entonces definir si estamos ante un fin de ciclo de transformaciones o sólo estamos en una fase del ciclo que dará origen a otras fases que volverá a ser dinámico el proceso de cambios latinoamericanos.

\section{Consuelo Sánchez: Me parece} importantísimo incluso a nivel mundial, porque todas las izquierdas en el manantial entraran en crisis y en América Latina se intenta primero parar el neoliberalismo e iniciar procesos de cambio, de transformación, y, en efecto, en cada país es diferente. Pero son los primeros intentos en el mundo y por eso ahorita América Latina es, alguna manera, un referente, tanto de la izquierda como de la derecha, porque también está siendo golpeada por toda esta constelación de la derecha a nivel internacional para tratar de golpear a las experiencias de intentos de creación de nuevas sociedades justas, igualitarias, etcétera. La primera ensayo, la primera experiencia fue a la de Venezuela, que ahí sigue y ahí está tratando de con todos los avances, problemas, errores, lo que sea, pero está tratando de construir sociedades diferentes, justas, igualitarias, con todas sus dificultades. $\mathrm{Y}$ esto es experiencia interesante, muy golpeada, pero acaba de tener sin mostrar que tiene en cuenta con un gran apoyo popular, tanto es así que ganaron la mayoría de las gubernaturas en elecciones recientes, y eso lo coloca de nuevo una posición diferente, políticamente, en el plano nacional e internacional. Estaba siendo muy golpeado con un intento de derrocar a Maduro, afortunadamente esto no se logró, porque hay que defender estos procesos, son procesos importantes y sobre todo hay que defender el derecho a la autodeterminación de los pueblos, la no intervención. Eso es lo que tenemos como izquierda en América Latina, exigirlo. Es decir, ellos están llevando a cabo un proceso interno de cambio, hay conflictos internos, pero solo tiene que resolver el propio pueblo venezolano, sin la intervención de ningún otro país. Y eso es importantísimo, el respeto a la autodeterminación y no la intervención. Rechazar siempre la intervención. La otra es Bolivia, que es un proceso muy interesante. Como ustedes saben, Evo Morales que viene de un movimiento, es apoyado por un conjunto de movimientos que se habían revelado en lo que ya se llama la "Guerra del Agua" o la 
"Guerra del Gas", que son luchas populares en contra de la privatización del agua y del gas, y de ahí se crea un gran movimiento que lleva a Evo a la Presidencia y después a la constituyente. Y esa constituyente elabora una construcción muy avanzada, muy avanzada, que crean el estado plurinacional, las autonomías de los pueblos y se intenta construir un estado realmente plurinacional. Intenta construir una institucionalidad diferente, que dé respuesta a esa diversidad de nacionalidades indígenas, ahí, pues la población indígena en términos demográficos es más del $50 \%$, entonces tiene una gran presencia. Entonces allí, también en términos económicos, hay una redistribución de la riqueza que ha significado el mejoramiento de las condiciones de vida de la mayoría de la población de Bolivia y también en Venezuela. Tenemos aquí es que es no solamente económica es política hay ahí un conflicto político económico y que se manifiesta de distintas maneras. Entonces Bolivia hay una experiencia y un proceso que está en marcha, está en curso, con todas sus contradicciones, pero es un proceso muy interesante también. En Ecuador igual, donde se intenta también construir una un país diferente, también con sus problemas y muy interesante porque también lo que hicieron estos gobiernos es mejorar las condiciones de vida de su población ampliar la educación a todos los sectores, de la salud, la alimentación y etcétera-. Más ahí también vamos con conflictos internos, pero son intentos son experiencias interesantes en este proceso. Bueno, en el caso de Brasil es también un referente para para América Latina, con Lula y lo que pasa ahorita para nosotros también pues es un golpe. Lo que pase en cualquier paso de partes de América Latina nos afecta a todos. Pues América Latina somos todos. Y si le va muy bien a alguno de nuestros países, pues nos va bien a todos. Y si le va mal a uno eso, nos duele a los demás. Entonces sí, lo que pasó en Brasil nos preocupa mucho. Ese golpe de estado que se dio y la presencia de lo que se dice presidente, que llega ahí no de manera democrática y precisamente en los cambios y retrocesos que está significando eso para el pueblo de Brasil. Entonces sí, nos preocupa mucho, nos interesa muchísimo que vuelvan a retomar el rumbo de la izquierda que ha sido muy importante, también ver así en el caso de argentina es decir son experiencias muy diversas, procesos muy distintos, y que se encuentran en etapas diferentes. Como en el caso de Brasil, esperamos, creemos y estamos convencidos que el pueblo brasileño va a volver a tomar el camino que habían dado. 